\title{
The effect of Nannochloropsis oceanica feed inclusion on rabbit muscle proteome
}

Author links open overlay

panelD.M.RibeiroaJ.BandarrinhaaP.NannibS.P.Alves'C C.F.MartinsªR.J.B.BessacL.Falcão-e-

Cunha ${ }^{A}$ A.M.Almeida ${ }^{a}$

Show more

Add to Mendeley

Share

Cite

https://doi.org/10.1016/j.jprot.2020.103783Get rights and content

\section{Highlights}

-

Nannochloropsis oceanica feed inclusion does not affect animal performance.

\section{$\bullet$}

Control rabbits have higher abundance of structural proteins in the muscle.

-

Dietary Nannochloropsis oceanica seems to affect amino acid metabolism in the muscle of rabbits.

\section{Abstract}

Nannochloropsis oceanica is a microalga, highly concentrated in protein and EPA (eicosapentaenoic acid). It has a recalcitrant cell wall that decreases nutrient 
digestibility. The objective of this study is to evaluate the effect of Nannochloropsis oceanica feed inclusion on the muscle proteome of fattening rabbits.

Twenty rabbits were housed in individual cages for 5 weeks and were fed a control diet $(n=10)$ and one with $4.45 \%$ inclusion of microalga, replacing whole soybean meal $(\mathrm{n}=10)$. After slaughter, samples of gastrocnemius muscle were taken for labelfree proteomic analysis.

A total of 1497 proteins were identified, 46 with differential abundance. Control rabbits had high abundance of proteins related to protein metabolism, suggesting higher muscle protein turnover. They also had higher abundance of structural proteins, suggesting a less tender meat by comparison with algae-fed rabbits. These had high abundance of proteins related to amino acid catabolism (Phe, Tyr) and synthesis (Gln). In addition, they had high abundance of proteins related to protein breakdown, overall suggesting that more tender meat may result from algae feeding.

\section{Biological significance}

Microalgae are interesting feedstuffs particularly from a sustainability point of view. Their use in farm animal diets could simultaneously enhance the nutritional value and quality of meat. However, the biochemical pathways behind such improvement remain uncharacterized, namely in the rabbit species. By using a proteomics approach, this study will enlighten such biochemical pathways and relate them with productive performance parameters. In addition, results reflect some anti-nutritional properties of the recalcitrant cell wall over amino acid digestibility and consequently, its availability for protein synthesis.

\section{Graphical abstract}

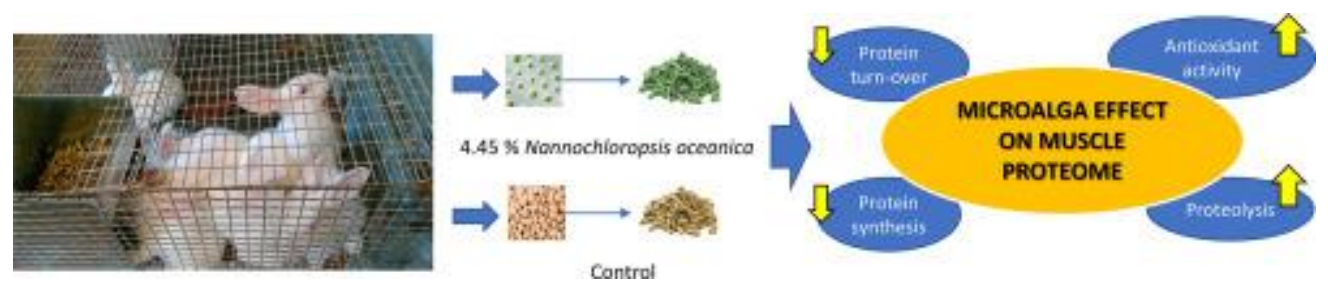

1. Download: Download high-res image (324KB)

2. Download: Download full-size image

- Previous article in issue 
- Next article in issue

\section{Keywords}

Rabbit

Nannochloropsis oceanica

Muscle proteome

\section{Introduction}

The interest in microalgae such as Tetraselmis sp., Chlorococcum sp., Chlorella sp., Arthrospira sp. and Nannochloropsis sp. has increased in recent years. Such interest is mostly related to their use as a source of food, feed and fuel. This is particularly important in the current context of population increase that is predicted to rise to 9 billion by 2050 [1]. Microalgae are particularly interesting in the context of animal production sustainability [2]. Indeed, and in addition of being an interesting alternative to traditional crops such as corn or soybean that have a very intensive use of land and production factors (fertilization, land mobilization, etc.), microalgae have been reported to be an interesting source of protein, essential amino acids, polyunsaturated fatty acids (PUFA), minerals, vitamins and pigments. Additionally, the incorporation of microalgae biomass in animal feed positively enhances the immune response and gut function [2].

Nannochloropsis oceanica (NCO) is an understudied microalga in the context of animal nutrition. It is reported to have a crude protein content between 28.7 and $47.7 \%$ and approximately $120 \mathrm{mg}$ fatty acids/g dry matter (DM), with eicosapentaenoic acid (EPA) representing 29 to $39 \%$ of total fatty acid content [3, 4$]$. This nutrient profile makes it an interesting alternative by comparison to other feed sources, particularly soybean, in addition to being more environmentally sustainable [5]. Moreover, microalgae could be part of a solution to reduce Europe's dependency on soybean imports [3]. Like other microalgae, NCO's nutritive value varies substantially with production conditions [2]. EPA and other n-3 long-chain PUFA such as docosahexaenoic acid (DHA), have a high interest for human diets as healthy (e.g. anti-thrombotic), particularly effective in the prevention of heart conditions [6,7]]. 
Feeding animals with NCO could enrich their products with such n-3 PUFA. Nevertheless, microalgae have a recalcitrant cell wall that conditions its digestion by monogastric animals such as poultry, swine and rabbits []․ Interestingly, and unlike other microalgae such as Spirulina [8], little information is available in the literature on the use of NCO in animal feeding. An exception is the work of Skrede et al. [4] that replaced fishmeal with NCO in adult mink (Mustela vison) diets. Increased levels of $\mathrm{NCO}(60,120$ and $240 \mathrm{~g} / \mathrm{kg})$ have compromised both the crude protein and lipid fraction digestibility, which was related to the cell wall structure, as well as lipase inhibitor proteins in the cell wall surface.

The rabbit (Oryctolagus cuniculus) is extensively used in certain areas of the globe as a meat producing animal. Indeed, it is highly appreciated in the Mediterranean basin, from North Africa to Southern European countries such as Portugal, Spain, Italy and France [9] that in the year 2017 produced approximately 112,030 t of rabbit meat according to FAOSTAT. Rabbits have interesting productive traits, particularly suitable for small scale industrial production systems and its meat is characterized as being lean, with low fat and cholesterol contents and a favourable content of unsaturated fatty acids (UFA) and linolenic acid. The fatty acid profile of rabbit meat can furthermore be easily altered by changing their diet and the production of enriched meat with n-3 PUFA have been accomplished [10].

The topic of microalgae on animal feed has been reviewed previously [2]. Still, few microalgae have been studied in rabbit diets. The inclusion of Arthrospira platensis (or Spirulina) in rabbit diets lowered digestibility and increased feed ingestion at 10\% feed inclusion, thus lowering feed efficiency [11]. The studies reviewed by Holman and Malau-Aduli [8] furthermore suggest an increased oxidative stability of the meat of rabbits fed with Spirulina. In addition, feeding Schizochytrium sp. algal biomass, highly concentrated in DHA, increased EPA, DHA, linoleic and linolenic acid contents in rabbit meat [12]. In other studies, New Zealand White rabbits were fed with a diet containing 10\% Nannochloropsis oculata meal [13]. It decreased crude fat and acid detergent fibre (ADF) apparent digestibility, in contrast to the apparent digestibility of DM, neutral detergent fibre (NDF) and ash, which increased when animals were fed the algal meal, with no reports for fatty acid profiles of meat. Because algal biomass was included as a meal a by-product of oil extraction - its purpose was to use it as a protein source, and it was 
not regarded as a functional feed towards the enrichment of rabbit meat with n-3 PUFA.

Rabbit tissue proteomics in the context of animal production is somewhat scarce as studies involving rabbits and muscle proteomics are usually in a context of biomedical research. For a review, kindly refer to Miller et al. [9]. Some studies have aimed at mapping [14] and studying [15] the gastrocnemius muscle of rabbits, using gel-based approaches that are limited in their capacity to perform an in-depth characterization of a tissue's proteome. Later, authors reported the identification and characterization of the sarcoplasmic reticulum proteome using a shotgun approach, which resulted in the identification of 483 proteins [16]. The same team later identified 459 proteins in mitochondrion-associated membrane of rabbit skeletal muscle [17]. By using LCMS/MS technology, our side objective is to perform an in-depth proteome characterization of the whole rabbit gastrocnemius muscle proteome, similarly to what has been reported in other species $[18,19]$.

To our knowledge, this is the first study to assess the effect dietary inclusion of microalgae in the muscle proteome of rabbits. By using proteomics, it is possible to unravel the biochemical pathways affected by NCO ingestion and relate such results with animal performance and/or meat quality. In this study, the objective is to evaluate the effect of NCO inclusion in rabbit diets, as a replacement of whole soybean, on the muscle proteome.

\section{Materials and methods}

\subsection{Animals and experimental design}

The experiment was conducted at the animal production facilities of the Instituto Superior de Agronomia (Lisboa, Portugal). The experiment consisted of a digestibility trial, following procedures as previously reported [20,21]. Please report to these publications for details on animal facilities. Briefly, 20 commercial hybrid (Hyplus ${ }^{\circledR}$, Hypharm, Sèvremoine, France) rabbits (Oryctolagus cuniculus), aged 35 days, were divided in two nutritional treatments $(n=10)$ : control (SA) and fed with a $4.45 \%$ inclusion of Nannochloropsis oceanica as a replacement of whole soybean (AA). Animals belonged to both sexes as established by Zhu et al. [22]. Their average initial live weight was 964 and $992 \pm 79.89$ g, respectively. Rabbits were kept in individual 
cages with ad libitum access to fresh water. Diet composition and nutritional value is presented in Table 1. Feed intake and animal growth was measured daily and weekly, respectively. The trial lasted 5 weeks, at the end of which animals were subjected to electrical stunning followed by slaughtering by exsanguination. Both rabbit growth and slaughtering used standard commercial practises used in rabbit meat production in Portugal. Productive performance (animal growth, feed conversion ratio, average daily gain, carcass yield, perirenal fat weight and meat colour) was determined and statistically analyzed as previously described $[\underline{21}, \underline{23}]$. Immediately after slaughter, the gastrocnemius muscle was sampled and frozen at $-80{ }^{\circ} \mathrm{C}$ until further analysis.

Table 1. Feedstuffs used in the experimental diets and their nutritional composition.

Feed component (\%)

$\begin{array}{ccc}\text { Corn } & 20 & 20 \\ \text { Wheat bran } & 10 & 10 \\ \text { Soybean meal } & 16 & 15 \\ \text { Sunflower cake } & 7.5 & 7.5 \\ \text { Alfalfa } & 25 & 25 \\ \text { Grass straw } & 12 & 12 \\ \text { Beat pulp } & 5 & 4.74 \\ \text { Whole soybean } & 3 & 0 \\ \text { Nannochloropis oceanica } & 0 & 4.45 \\ \text { Mineral and vitamin premix } & & 0.2 \\ \text { Sodium chloride } & 0.2 & 0.5 \\ \text { Calcium phosphate } & 0.5 & 0.5 \\ \text { DL-methionine } & 0.5 & \end{array}$


L-lysine

Nutritional composition (\% in dry matter - DM)

Dry matter

Organic matter

Crude protein

Crude fat

Neutral detergent fibre (NDF)

Acid detergent fibre (ADF)

Acid detergent lignin (ADL)

Energy (kcal/kg DM)
91.53

91.68

18.45

3.49

39.31

22.02

4.29

4435.84
0.05

90.44

91.33

18.06

3.19

38.77

21.55

4.18

4430.41

a

Premix composition (added per kg of feed): vitamin A - 1000 UI; vitamin D3-1500 UI; vitamin E 15 mg; vitamin K3-1.5 mg; vitamin B1-1 mg; vitamin B2-2 mg; vitamin B6-1.5 mg; vitamin B12$0.01 \mathrm{mg}$; pantothenic acid $-8 \mathrm{mg}$; nicotinic acid $-25 \mathrm{mg}$; biotin $-0.02 \mathrm{mg}$; betaine $-136.5 \mathrm{mg}$; robenidine - $50 \mathrm{mg}$; Co - $0.7 \mathrm{mg}$; Cu - $5 \mathrm{mg}$; Fe - 30 mg; I - $1 \mathrm{mg}$; Mn - 15 mg; Se - 0.2 mg; Zn $30 \mathrm{mg}$; ethoxyquin $-12.5 \mathrm{mg}$.

\subsection{Animal welfare disclaimer}

The trial was conducted according to European Union experimental animal welfare guidelines (European Union procedures on animal experimentation - Directive 2010/63/EU) on animal experimentation on farm conditions and replicating standard commercial practises. Author André M. Almeida holds a FELASA (Federation of European Laboratory Animal Society Associations) grade C certificate that enables planning and execution of animal experiments under European Union regulations. 


\subsection{Sample preparation}

Six samples per group were randomly selected and used for proteomic analysis. For each sample, proteins were extracted using a tissue homogenizer (TissueLyser II, QUIAGEN, Germantown, MD, USA) and digested using a commercial kit iST Kit (PreOmics, Planegg, Germany). Briefly, $50 \mu \mathrm{l}$ of Lyse buffer and around $20 \mu \mathrm{g}$ of glass beads (425-500 $\mu \mathrm{m}$, Sigma Aldrich, St. Louis, MO, USA) were added to 3 to $5 \mathrm{mg}$ of thawed tissue. After two cycles of protein extraction (of 2 min each at $30 \mathrm{~Hz}$ ), tubes were centrifuged at $16,100 \mathrm{~g}$ for $15 \mathrm{~min}$, and supernatant was pipetted into a fresh microcentrifuge tube for proteomic analysis. The solubilization of the extracted proteins was enhanced processing the samples with High Intensity Focused Ultrasound (HIFU) for 1 min setting the ultrasonic amplitude to 65\%. After 1:5 dilution with water, the protein concentration was estimated using the Qubit ${ }^{\circ}$ Protein Assay Kit (Life Technologies, Zurich, Switzerland). For each sample, $100 \mu \mathrm{g}$ of protein were transferred to the cartridge and digested adding $50 \mu \mathrm{l}$ of the "Digest" solution. After $60 \mathrm{~min}$ of incubation at $37^{\circ} \mathrm{C}$ the digestion was stopped with $100 \mu \mathrm{l}$ of Stop solution following manufacturer's instructions. The solutions in the cartridge were removed by centrifugation at $3800 \mathrm{~g}$, while the peptides were retained by the iST-filter. Finally, peptides were washed, eluted, dried and re-solubilized in $20 \mu 1$ of injection buffer ( $3 \%$ acetonitrile, $0.1 \%$ formic acid). Prior to LC-MS analysis, samples were further diluted 1:10 with injection buffer.

\subsection{Liquid chromatography - mass spectrometry analysis}

Mass spectrometry analysis was performed on a Q Exactive HF-X mass spectrometer (Thermo Scientific) equipped with a Digital PicoView source (New Objective, Woburn, MA, USA) and coupled to a M-Class UPLC (Waters, Milford, MA, USA). Solvent composition at the two channels was $0.1 \%$ formic acid for channel A and $0.1 \%$ formic acid, $99.9 \%$ acetonitrile for channel B. For each sample, $2 \mu 1$ of peptides were loaded on a commercial MZ Symmetry C18 Trap Column (100A, $5 \mu \mathrm{m}$, $180 \mu \mathrm{m} \times 20 \mathrm{~mm}$, Waters, Milford, MA, USA) followed by nanoEase MZ C18 HSS T3 column (100 A, $1.8 \mu \mathrm{m}, 75 \mu \mathrm{m} \times 250 \mathrm{~mm}$, Waters, Milford, MA, USA). The peptides were eluted at a flow rate of $300 \mathrm{nl} / \mathrm{min}$ by a gradient from 8 to $27 \% \mathrm{~B}$ in $82 \mathrm{~min}, 35 \%$ B in $5 \mathrm{~min}$ and $80 \%$ B in $1 \mathrm{~min}$. Samples were acquired in a randomized 
order. The mass spectrometer was operated in data-dependent mode (DDA), acquiring a full-scan MS spectra $(350-1400 \mathrm{~m} / \mathrm{z})$ at a resolution of 120,000 at $200 \mathrm{~m} / \mathrm{z}$ after accumulation to a target value of 3,000,000, followed by HCD (higher-energy collision dissociation) fragmentation on the twenty most intense signals per cycle. HCD spectra were acquired at a resolution of 15,000 using a normalized collision energy of 28 and a maximum injection time of $22 \mathrm{~ms}$. The automatic gain SA (AGC) was set to 100,000 ions. Charge state screening was enabled. Singly, unassigned, and charge states higher than seven were rejected. Only precursors with intensity above 110,000 were selected for MS/MS. Precursor masses previously selected for MS/MS measurement were excluded from further selection for $30 \mathrm{~s}$ and the exclusion window was set at $10 \mathrm{ppm}$. The samples were acquired using internal lock mass calibration on $\mathrm{m} / \mathrm{z} 371.1012$ and 445.1200. The mass spectrometry proteomics data were handled using the local laboratory information management system (LIMS) [24].

\subsection{Protein identification and label free protein quantification}

The acquired raw MS data were processed by MaxQuant (version 1.6.2.3), followed by protein identification using the integrated Andromeda search engine [25]. Spectra were searched against a Uniprot Oryctolagus cuniculus (rabbit) reference proteome (taxonomy 9986, canonical version from 2018 to 11-23), concatenated to its reversed decoyed FASTA database and common protein contaminants. Carbamidomethylation of cysteine was set as fixed modification, while methionine oxidation and $\mathrm{N}$-terminal protein acetylation were set as variable. Enzyme specificity was set to trypsin/P allowing a maximum of two missed cleavages. MaxQuant Orbitrap default search settings were used. The maximum false discovery rate (FDR) was set to 0.01 for peptides and 0.05 for proteins. Label free quantification was enabled and a $2 \mathrm{~min}$ window for match between runs was applied. In the MaxQuant experimental design template, each file is kept separate in the experimental design to obtain individual quantitative values. Protein fold changes were computed based on intensity values reported in the proteinGroupts.txt file. A set of functions implemented in the $\mathrm{R}$ package SRMService [26] was used to filter for proteins with 2 or more peptides allowing for a maximum of 5 missing values, and to normalize the data with a modified robust $\mathrm{z}$-score transformation and to compute $p$-values using the $t$-test with 
pooled variance. If all measurements of a protein are missing in one of the conditions, a pseudo fold change was computed replacing the missing group average by the mean of $10 \%$ smallest protein intensities in that condition.

\subsection{Proteome characterization and protein interactions}

The resulting 1497 protein accessions successfully identified were used for proteome characterization, by performing a search in the PANTHER scoring tool [27], using the Oryctolagus cuniculus reference proteome. For characterization of the differentially abundant proteins the same method was used, but only for the 46 proteins found to be differentially abundant, and with separate searches for those that have higher abundance in each group. Proteins were considered differentially abundant when $p<0.05$ and $\log 2 \mathrm{FC}$ was under/over \pm 0.56 . To obtain protein-protein interactions, these 46 proteins were searched in the STRING search engine [28] for the rabbit (Oryctolagus cuniculus) organism. The interactions were obtained with a confidence $>0.7$ and hiding nodes with no interaction.

\section{Results}

\subsection{Animal production performance}

Overall, growth performance was unaffected by dietary treatment. Average final weights were 2.751 and $2.641 \mathrm{~kg}$ for SA and AA rabbits, respectively (Fig. 1A). Likewise, feed:gain ratio (Fig. 1B) was also unaffected, where SA rabbits and AA rabbits ingested 3.27 and $3.31 \mathrm{~g}$ of feed per $\mathrm{g}$ of live weight gained. Average daily gain followed the same trend (Fig. 1H). Other parameters such as cooking loss of longissimus dorsi (Fig. 1C), carcass yield (Fig. 1D), perirenal fat weight (Fig. 1F) and CP content of leg meat (Fig. 1G) were unaffected by NCO incorporation. The same occurred in the digestibility of $\mathrm{CP}$ of the experimental diets (Fig. 1E). These results will be presented in detail in a companion paper and are mentioned here solely to provide a context. 
A

Live Weights

B

Feed:Gain

3000.00

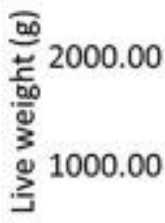

0.00
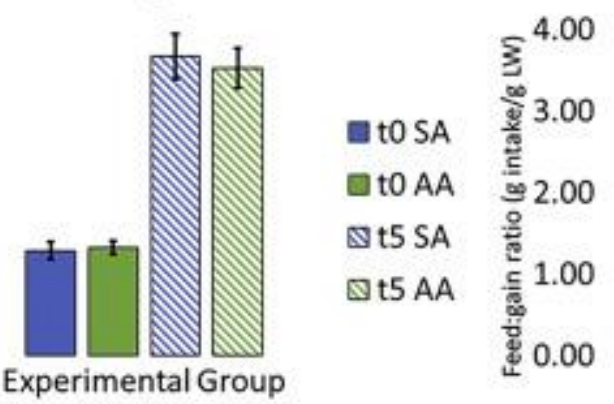

C

Cooking loss

30.00

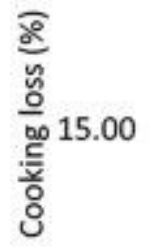

0.00

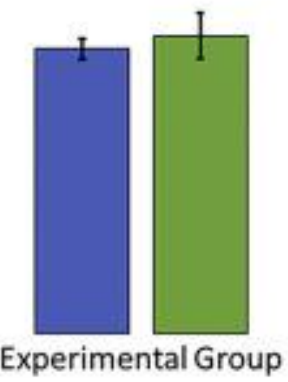

D

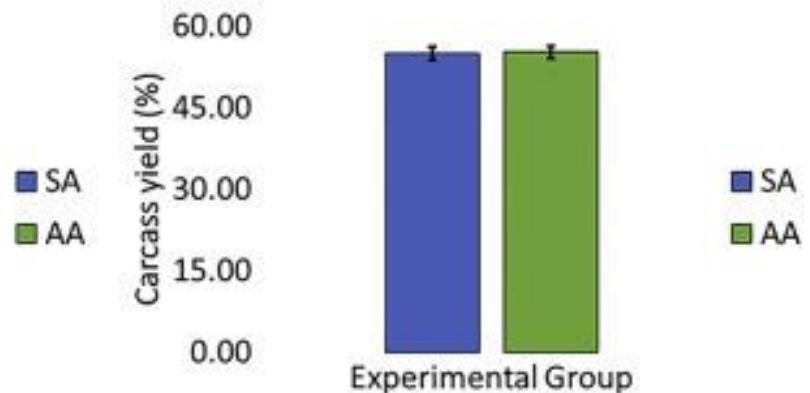

E Digestibility Coefficient (CP)

ळ 100.00

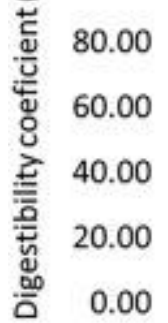

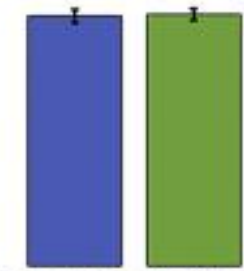

Experimental Group

G Crude Protein of Leg Meat (\% in DM)

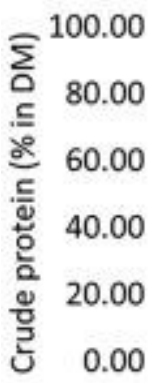
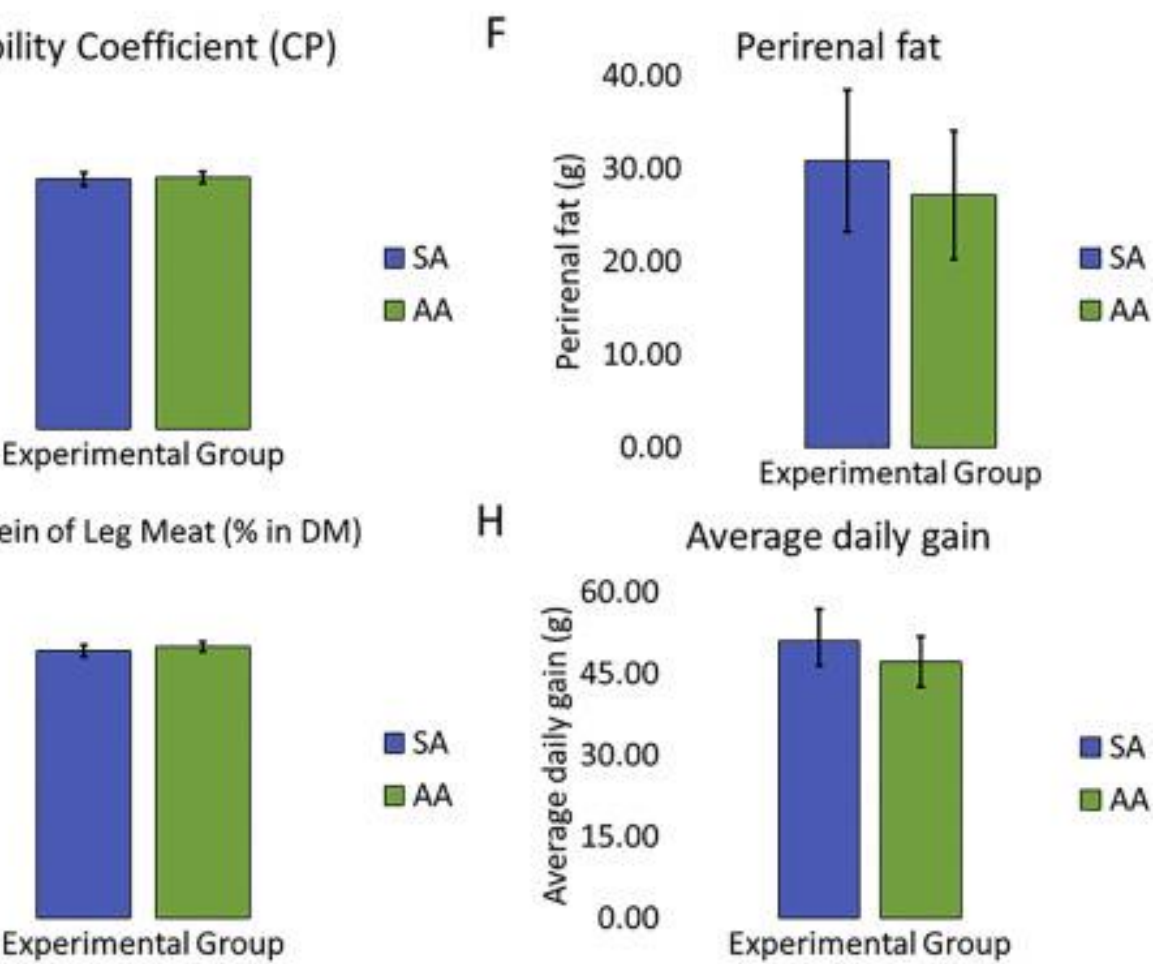

$\mathrm{H}$

Average daily gain
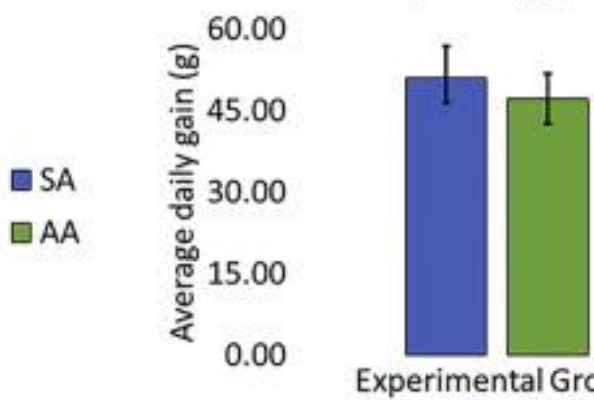

Experimental Group

aSA

$\square A A$

SA

$A A$

$S A$

AA

GSA

$\square A A$

1. Download: Download high-res image (329KB)

2. Download: Download full-size image

Fig. 1. Growth performance and carcass traits. A- live weights (initial - t0, final - t5), Bfeed:gain ratio, C-longissimus dorsi cooking loss, D- carcass yield, E- Digestibility 
coefficient, F- Perirenal fat, G- Crude protein of leg meat (\% in a dry matter -DM basis), $\mathrm{H}-$ Average daily gain.

\subsection{Proteome characterization}

A species-specific search in the Uniprot rabbit database with the generated spectra has resulted in the identification of 1497 proteins in the rabbit gastrocnemius muscle (Supplementary Table 1). Fig. 2 depicts a proteome characterization output using PANTHER, according to the GO terms: biological process (BP), molecular function (MF) and cellular component (CC). Regarding BP, the two major categories found were metabolic (16.1\%) and cellular processes (25.0\%). Major molecular functions were catalytic (30.4\%) and binding (37.5\%) activities. Cellular components corresponded mostly to cell $(32.1 \%)$ structures, with lesser categories following, such as organelle $(8.9 \%)$. 

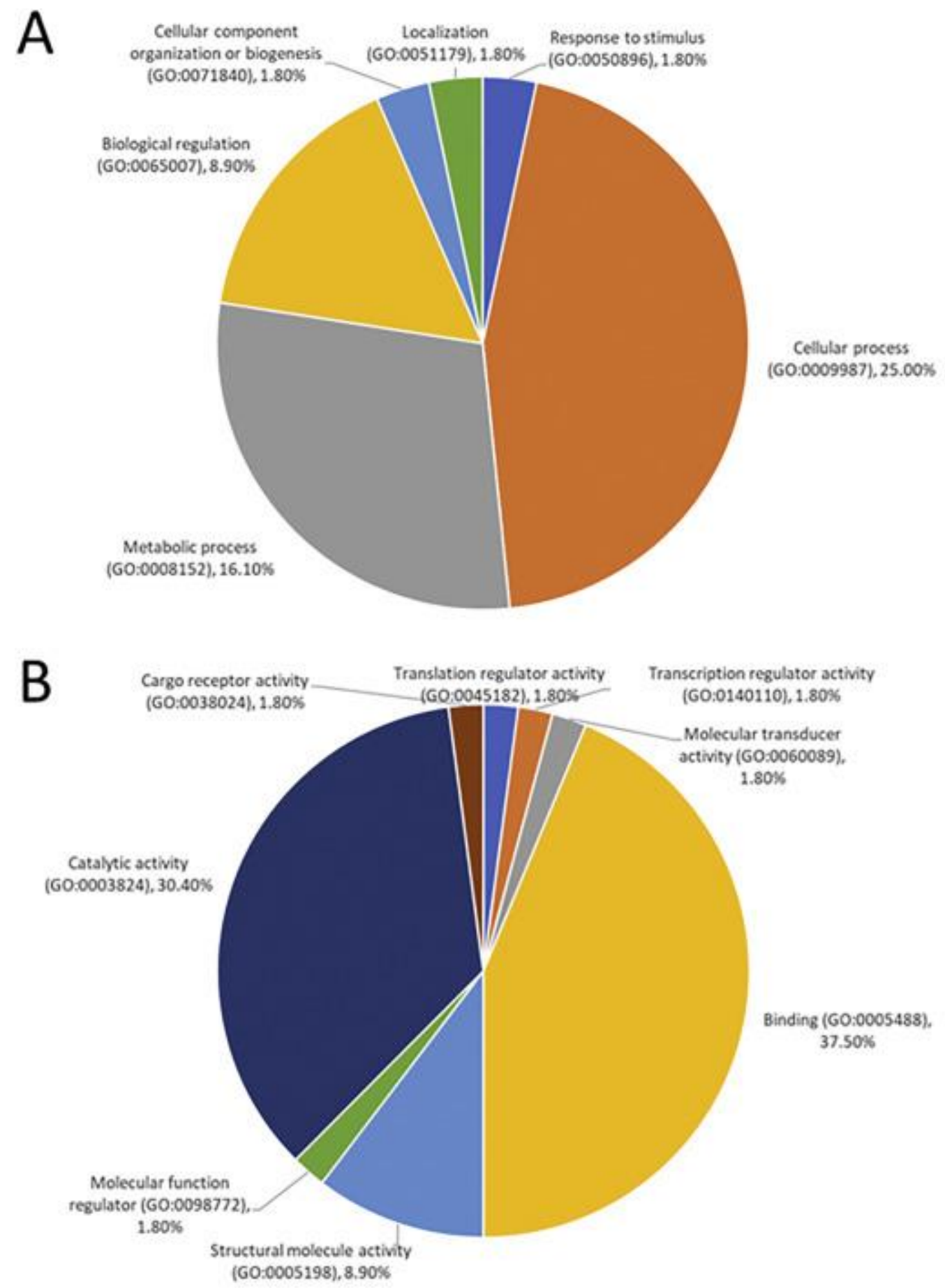

C

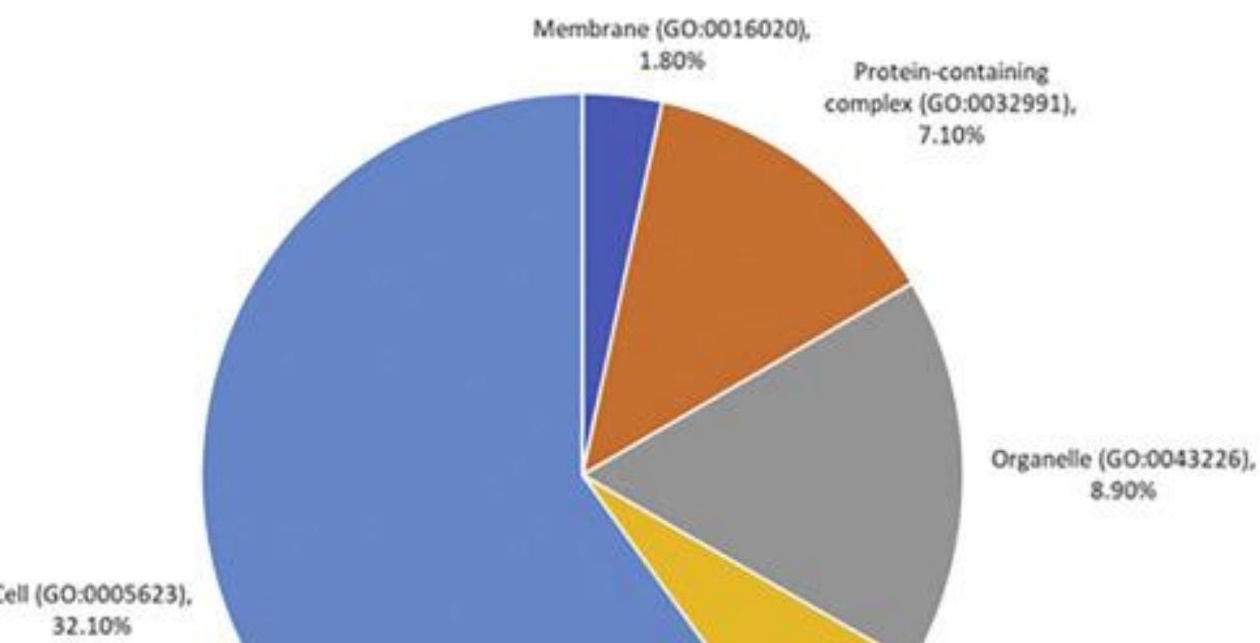


1. Download : Download high-res image (281KB)

2. Download: Download full-size image

Fig. 2. Proteome characterization of the gastrocnemius muscle of rabbits according to gene ontology. A- Biological Process; B- Molecular Function; C-Cellular component.

\subsection{Differential protein abundance}

The group comparison allowed the identification of 46 differentially abundant proteins (Table 2). Fig. 3 depicts a two volcano plots for normalized data and a heatmap with clustering depending on correlation and protein expression profiles (panel A and B). Both graphs demonstrate lack of clustering of the proteomic data. Following a molecular function characterization of these proteins (Fig. 3 - panel C), there were two categories that were unique for each group: molecular function regulator (1 sequence in AA) and structural molecule activity (3 sequences in SA). In both groups, binding was the most common category with 5 and 9 sequences identified for SA and AA rabbits, respectively. The interactions among these proteins, and their higher or lower abundance within groups, are presented in Fig. 4.

Table 2. Comparison of proteins with differentially abundant proteins (AA vs SA).

\begin{tabular}{|c|c|c|c|c|}
\hline $\begin{array}{l}\text { UniprotKB } \\
\text { Accession }\end{array}$ & Gene name & Protein name & $\log 2 \mathrm{FC}$ & P.Value \\
\hline T5B1_RABIT & KERA & $\begin{array}{l}\text { Uncharacterized protein OS=Oryctolagus } \\
\text { cuniculus OX }=9986 \mathrm{GN}=\mathrm{KERA} \mathrm{PE}=4 \mathrm{SV}=1\end{array}$ & -3.13 & 0.011 \\
\hline & & Eukaryotic translation initiation factor 3 subunit $\mathrm{M}$ & & \\
\hline 1SLW8_RABIT & EIF3M & $\begin{array}{l}\mathrm{OS}=\text { Oryctolagus cuniculus } \mathrm{OX}=9986 \mathrm{GN}=\mathrm{EIF} 3 \mathrm{M} \mathrm{PE}=1 \\
\mathrm{SV}=2\end{array}$ & -1.43 & 0.028 \\
\hline 1TUB8_RABIT & RPL11 & $\begin{array}{l}\text { Uncharacterized protein OS=Oryctolagus } \\
\text { cuniculus OX }=9986 \mathrm{GN}=\mathrm{RPL} 11 \mathrm{PE}=1 \mathrm{SV}=2\end{array}$ & -1.41 & 0.028 \\
\hline 1TUD6_RABIT & PSMC4 & $\begin{array}{l}\text { Proteasome } 26 \mathrm{~S} \text { subunit, ATPase } 4 \mathrm{OS}=\text { Oryctolagus } \\
\text { cuniculus OX }=9986 \mathrm{GN}=\mathrm{PSMC} 4 \mathrm{PE}=3 \mathrm{SV}=2\end{array}$ & -1.33 & 0.003 \\
\hline 1T4J4_RABIT & TUBB2B & $\begin{array}{l}\text { Tubulin beta chain OS=Oryctolagus cuniculus OX }=9986 \\
\mathrm{GN}=\mathrm{TUBB} 2 \mathrm{~B} \text { PE }=3 \mathrm{SV}=1\end{array}$ & -1.05 & 0.023 \\
\hline 3KPK3_RABIT & DIAPH2 & $\begin{array}{l}\text { Diaphanous related formin } 2 \mathrm{OS}=\text { Oryctolagus } \\
\text { cuniculus } \mathrm{OX}=9986 \mathrm{GN}=\mathrm{DIAPH} 2 \mathrm{PE}=4 \mathrm{SV}=1\end{array}$ & -1.03 & 0.019 \\
\hline
\end{tabular}




\begin{tabular}{|c|c|c|c|c|}
\hline $\begin{array}{l}\text { UniprotKB } \\
\text { Accession }\end{array}$ & Gene name & Protein name & $\log 2 \mathrm{FC}$ & P.Value \\
\hline G1T2M1_RABIT & YTHDC2 & $\begin{array}{l}\text { Uncharacterized protein OS=Oryctolagus } \\
\text { cuniculus } \mathrm{OX}=9986 \mathrm{GN}=\mathrm{YTHDC} 2 \mathrm{PE}=4 \mathrm{SV}=2\end{array}$ & -0.85 & 0.002 \\
\hline G1SQ11_RABIT & ALDH18A1 & $\begin{array}{l}\text { Delta-1-pyrroline-5-carboxylate synthase OS=Oryctolagus } \\
\text { cuniculus } \mathrm{OX}=9986 \mathrm{GN}=\mathrm{ALDH} 18 \mathrm{~A} 1 \mathrm{PE}=3 \mathrm{SV}=1\end{array}$ & -0.84 & 0.022 \\
\hline G1T5U2_RABIT & - & $\begin{array}{l}\text { Uncharacterized protein OS=Oryctolagus } \\
\text { cuniculus OX }=9986 \mathrm{PE}=3 \mathrm{SV}=1\end{array}$ & -0.76 & 0.027 \\
\hline G1SSV1_RABIT & COPS8 & $\begin{array}{l}\text { Uncharacterized protein OS=Oryctolagus } \\
\text { cuniculus OX }=9986 \mathrm{GN}=\mathrm{COPS} 8 \mathrm{PE}=4 \mathrm{SV}=1\end{array}$ & -0.76 & 0.035 \\
\hline G1T221_RABIT & TPM3 & $\begin{array}{l}\text { Tropomyosin } 3 \text { OS=Oryctolagus cuniculus OX }=9986 \\
\mathrm{GN}=\mathrm{TPM} 3 \mathrm{PE}=3 \mathrm{SV}=1\end{array}$ & -0.70 & 0.040 \\
\hline G1TG28_RABIT & BASP1 & $\begin{array}{l}\text { Brain abundant membrane attached signal protein } 1 \\
\text { OS=Oryctolagus cuniculus } \mathrm{OX}=9986 \mathrm{GN}=\mathrm{BASP} 1 \mathrm{PE}=4 \\
\mathrm{SV}=2\end{array}$ & -0.70 & 0.022 \\
\hline G1SVW5_RABIT & RPL4 & $\begin{array}{l}\text { Uncharacterized protein OS=Oryctolagus } \\
\text { cuniculus } \mathrm{OX}=9986 \mathrm{GN}=\mathrm{RPL} 4 \mathrm{PE}=1 \mathrm{SV}=2\end{array}$ & -0.63 & 0.038 \\
\hline B7NZD0_RABIT & TMOD4 & $\begin{array}{l}\text { Tropomodulin } 4 \text { (Predicted) OS=Oryctolagus } \\
\text { cuniculus OX }=9986 \mathrm{GN}=\mathrm{TMOD} 4 \mathrm{PE}=4 \mathrm{SV}=1\end{array}$ & -0.58 & 0.031 \\
\hline U3KPIO_RABIT & RPS15A & $\begin{array}{l}\text { Uncharacterized protein OS=Oryctolagus } \\
\text { cuniculus OX }=9986 \mathrm{GN}=\mathrm{RPS} 15 \mathrm{~A} \mathrm{PE}=4 \mathrm{SV}=1\end{array}$ & -0.57 & 0.042 \\
\hline G1T7B8_RABIT & ZNF532 & $\begin{array}{l}\text { Uncharacterized protein OS=Oryctolagus } \\
\text { cuniculus OX }=9986 \mathrm{GN}=\mathrm{ZNF5} 32 \mathrm{PE}=4 \mathrm{SV}=2\end{array}$ & -0.57 & 0.034 \\
\hline G1SQ37_RABIT & - & $\begin{array}{l}\text { Uncharacterized protein OS=Oryctolagus } \\
\text { cuniculus OX }=9986 \mathrm{PE}=4 \mathrm{SV}=1\end{array}$ & -0.57 & 0.034 \\
\hline G1SJM1_RABIT & $\mathrm{APOH}$ & $\begin{array}{l}\text { Uncharacterized protein OS=Oryctolagus } \\
\text { cuniculus } \mathrm{OX}=9986 \mathrm{GN}=\mathrm{APOH} \mathrm{PE}=4 \mathrm{SV}=2\end{array}$ & 0.57 & 0.022 \\
\hline G1SIH1_RABIT & PSME2 & $\begin{array}{l}\text { Uncharacterized protein OS=Oryctolagus } \\
\text { cuniculus } \mathrm{OX}=9986 \mathrm{GN}=\mathrm{PSME} 2 \mathrm{PE}=4 \mathrm{SV}=1\end{array}$ & 0.57 & 0.019 \\
\hline
\end{tabular}




\begin{tabular}{|c|c|c|c|c|}
\hline $\begin{array}{l}\text { UniprotKB } \\
\text { Accession }\end{array}$ & Gene name & Protein name & $\log 2 \mathrm{FC}$ & P.Value \\
\hline G1SYD3_RABIT & YARS & $\begin{array}{l}\text { Tyrosine-tRNA ligase OS=Oryctolagus cuniculus OX = } 9986 \\
\mathrm{GN}=\text { YARS PE }=3 \mathrm{SV}=1\end{array}$ & 0.58 & 0.047 \\
\hline G1TVS4_RABIT & $\mathrm{HPX}$ & $\begin{array}{l}\text { Hemopexin OS=Oryctolagus cuniculus } \mathrm{OX}=9986 \mathrm{GN}=\mathrm{HPX} \\
\mathrm{PE}=3 \mathrm{SV}=1\end{array}$ & 0.59 & 0.042 \\
\hline G1T752_RABIT & MCTS1 & $\begin{array}{l}\text { Malignant T-cell-amplified sequence OS=Oryctolagus } \\
\text { cuniculus OX }=9986 \mathrm{GN}=\mathrm{MCTS} 1 \mathrm{PE}=3 \mathrm{SV}=1\end{array}$ & 0.60 & 0.041 \\
\hline G1SP97_RABIT & LUM & $\begin{array}{l}\text { Lumican OS=Oryctolagus cuniculus OX }=9986 \mathrm{GN}=\mathrm{LUM} \\
\mathrm{PE}=4 \mathrm{SV}=1\end{array}$ & 0.60 & 0.029 \\
\hline S10AA_RABIT & S100a10 & $\begin{array}{l}\text { Protein S100-A10 OS=Oryctolagus cuniculus OX }=9986 \\
\mathrm{GN}=\mathrm{S} 100 \mathrm{a} 10 \mathrm{PE}=3 \mathrm{SV}=3\end{array}$ & 0.65 & 0.029 \\
\hline G1TKN7_RABIT & LOC100352197 & $\begin{array}{l}\text { Enhancer of rudimentary homolog OS=Oryctolagus } \\
\text { cuniculus OX }=9986 \mathrm{GN}=\mathrm{ERH} \mathrm{PE}=3 \mathrm{SV}=1\end{array}$ & 0.66 & 0.021 \\
\hline G1SQY8_RABIT & NUDC & $\begin{array}{l}\text { Uncharacterized protein OS=Oryctolagus } \\
\text { cuniculus } \mathrm{OX}=9986 \mathrm{GN}=\mathrm{NUDC} \mathrm{PE}=4 \mathrm{SV}=1\end{array}$ & 0.67 & 0.042 \\
\hline G1T0W8_RABIT & FGB & $\begin{array}{l}\text { Fibrinogen beta chain OS=Oryctolagus } \\
\text { cuniculus } \mathrm{OX}=9986 \mathrm{GN}=\mathrm{FGB} \mathrm{PE}=4 \mathrm{SV}=2\end{array}$ & 0.70 & 0.025 \\
\hline S10A6_RABIT & S100A6 & $\begin{array}{l}\text { Protein S100-A6 OS=Oryctolagus cuniculus OX = } 9986 \\
\mathrm{GN}=\mathrm{S} 100 \mathrm{~A} 6 \mathrm{PE}=1 \mathrm{SV}=2\end{array}$ & 0.73 & 0.021 \\
\hline G1TMM7_RABIT & ANP32A & $\begin{array}{l}\text { Uncharacterized protein OS=Oryctolagus } \\
\text { cuniculus OX }=9986 \mathrm{GN}=\mathrm{ANP} 32 \mathrm{~A} \mathrm{PE}=4 \mathrm{SV}=2\end{array}$ & 0.73 & 0.018 \\
\hline G1TKX3_RABIT & FGG & $\begin{array}{l}\text { Uncharacterized protein OS=Oryctolagus } \\
\text { cuniculus } \mathrm{OX}=9986 \mathrm{GN}=\mathrm{FGG} \mathrm{PE}=4 \mathrm{SV}=1\end{array}$ & 0.76 & 0.020 \\
\hline G1SS91_RABIT & C4A & $\begin{array}{l}\text { Uncharacterized protein OS=Oryctolagus } \\
\text { cuniculus } \mathrm{OX}=9986 \mathrm{GN}=\mathrm{C} 4 \mathrm{~A} \mathrm{PE}=4 \mathrm{SV}=1\end{array}$ & 0.77 & 0.046 \\
\hline G1SZP0_RABIT & TOM1 & $\begin{array}{l}\text { Uncharacterized protein OS=Oryctolagus } \\
\text { cuniculus } \mathrm{OX}=9986 \mathrm{GN}=\mathrm{TOM} 1 \mathrm{PE}=3 \mathrm{SV}=1\end{array}$ & 0.78 & 0.019 \\
\hline
\end{tabular}




\begin{tabular}{|c|c|c|c|c|}
\hline $\begin{array}{l}\text { UniprotKB } \\
\text { Accession }\end{array}$ & Gene name & Protein name & $\log 2 \mathrm{FC}$ & P.Value \\
\hline G1SEIO_RABIT & SUOX & $\begin{array}{l}\text { Uncharacterized protein OS=Oryctolagus } \\
\text { cuniculus } \mathrm{OX}=9986 \mathrm{GN}=\mathrm{SUOX} \mathrm{PE}=4 \mathrm{SV}=1\end{array}$ & 0.80 & 0.028 \\
\hline CRYL1_RABIT & CRYL1 & $\begin{array}{l}\text { Lambda-crystallin OS=Oryctolagus cuniculus OX }=9986 \\
\mathrm{GN}=\mathrm{CRYL1} \mathrm{PE}=1 \mathrm{SV}=3\end{array}$ & 0.80 & 0.006 \\
\hline G1SKS9_RABIT & TXNRD1 & $\begin{array}{l}\text { Uncharacterized protein OS=Oryctolagus } \\
\text { cuniculus OX }=9986 \mathrm{GN}=\mathrm{TXNRD} 1 \mathrm{PE}=3 \mathrm{SV}=2\end{array}$ & 0.81 & 0.037 \\
\hline G1TAJ3_RABIT & LDHA & $\begin{array}{l}\text { L-lactate dehydrogenase OS=Oryctolagus } \\
\text { cuniculus OX }=9986 \mathrm{GN}=\mathrm{LDHA} P \mathrm{PE}=3 \mathrm{SV}=1\end{array}$ & 0.82 & 0.028 \\
\hline G1U7U3_RABIT & NME1 & $\begin{array}{l}\text { Nucleoside diphosphate kinase OS=Oryctolagus } \\
\text { cuniculus OX }=9986 \mathrm{GN}=\mathrm{NME} 1 \mathrm{PE}=3 \mathrm{SV}=1\end{array}$ & 0.84 & 0.048 \\
\hline G1U5W5_RABIT & NRDC & $\begin{array}{l}\text { Uncharacterized protein OS=Oryctolagus } \\
\text { cuniculus } \mathrm{OX}=9986 \mathrm{GN}=\mathrm{NRDC} \mathrm{PE}=4 \mathrm{SV}=1\end{array}$ & 0.91 & 0.047 \\
\hline G1SN16_RABIT & APEX1 & $\begin{array}{l}\text { DNA-(apurinic or apyrimidinic site) lyase OS=Oryctolagus } \\
\text { cuniculus OX }=9986 \mathrm{GN}=\mathrm{APEX} 1 \mathrm{PE}=3 \mathrm{SV}=1\end{array}$ & 0.95 & 0.024 \\
\hline G1SZT1_RABIT & RBKS & $\begin{array}{l}\text { Ribokinase OS }=\text { Oryctolagus cuniculus OX }=9986 \\
\mathrm{GN}=\mathrm{RBKS} P \mathrm{PE}=3 \mathrm{SV}=2\end{array}$ & 0.97 & 0.001 \\
\hline G1SW00_RABIT & GLUL & $\begin{array}{l}\text { Glutamate-ammonia ligase } \mathrm{OS}=\text { Oryctolagus } \\
\text { cuniculus } \mathrm{OX}=9986 \mathrm{GN}=\mathrm{GLUL} \mathrm{PE}=3 \mathrm{SV}=2\end{array}$ & 1.03 & 0.038 \\
\hline G1SN00_RABIT & KNG1 & $\begin{array}{l}\text { Uncharacterized protein OS=Oryctolagus } \\
\text { cuniculus } \mathrm{OX}=9986 \mathrm{GN}=\mathrm{KNG} 1 \mathrm{PE}=4 \mathrm{SV}=2\end{array}$ & 1.08 & 0.005 \\
\hline CAN1_RABIT & CAPN1 & $\begin{array}{l}\text { Calpain- } 1 \text { catalytic subunit (Fragment) OS=Oryctolagus } \\
\text { cuniculus } \mathrm{OX}=9986 \mathrm{GN}=\mathrm{CAPN} 1 \mathrm{PE}=1 \mathrm{SV}=1\end{array}$ & 1.08 & 0.030 \\
\hline G1SM91_RABIT & FAH & $\begin{array}{l}\text { Fumarylacetoacetate hydrolase OS=Oryctolagus } \\
\text { cuniculus OX }=9986 \mathrm{GN}=\mathrm{FAH} \mathrm{PE}=4 \mathrm{SV}=1\end{array}$ & 1.21 & 0.012 \\
\hline G1TYR3_RABIT & $\mathrm{KLC1}$ & $\begin{array}{l}\text { Kinesin light chain } 1 \text { OS=Oryctolagus cuniculus OX }=9986 \\
\mathrm{GN}=\mathrm{KLC1} \mathrm{PE}=4 \mathrm{SV}=2\end{array}$ & 1.23 & 0.001 \\
\hline
\end{tabular}


UniprotKB

Accession

G1T464_RABIT
Gene name

Protein name

log2FC P.Value

Uncharacterized protein OS=Oryctolagus

cuniculus OX $=9986 \mathrm{PE}=3 \mathrm{SV}=1$
2.30

0.004 
A

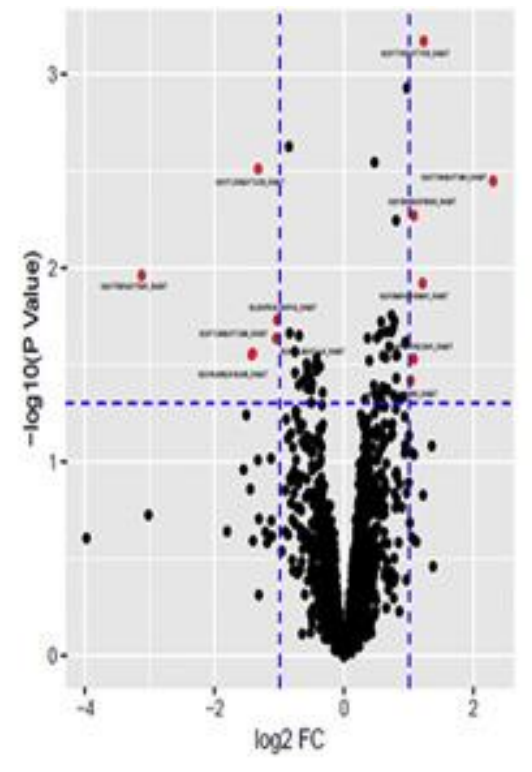

significance - Not Sig - Pvave <0.05 8 |bogefC|>

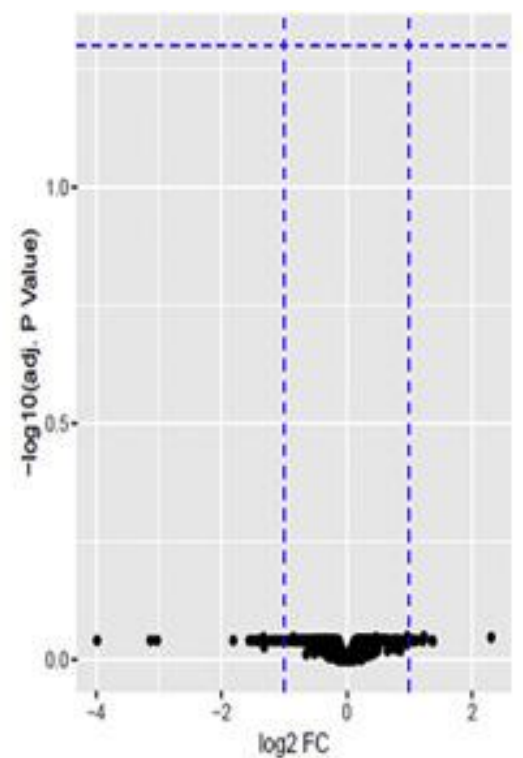

significance - Nor sig

B

c
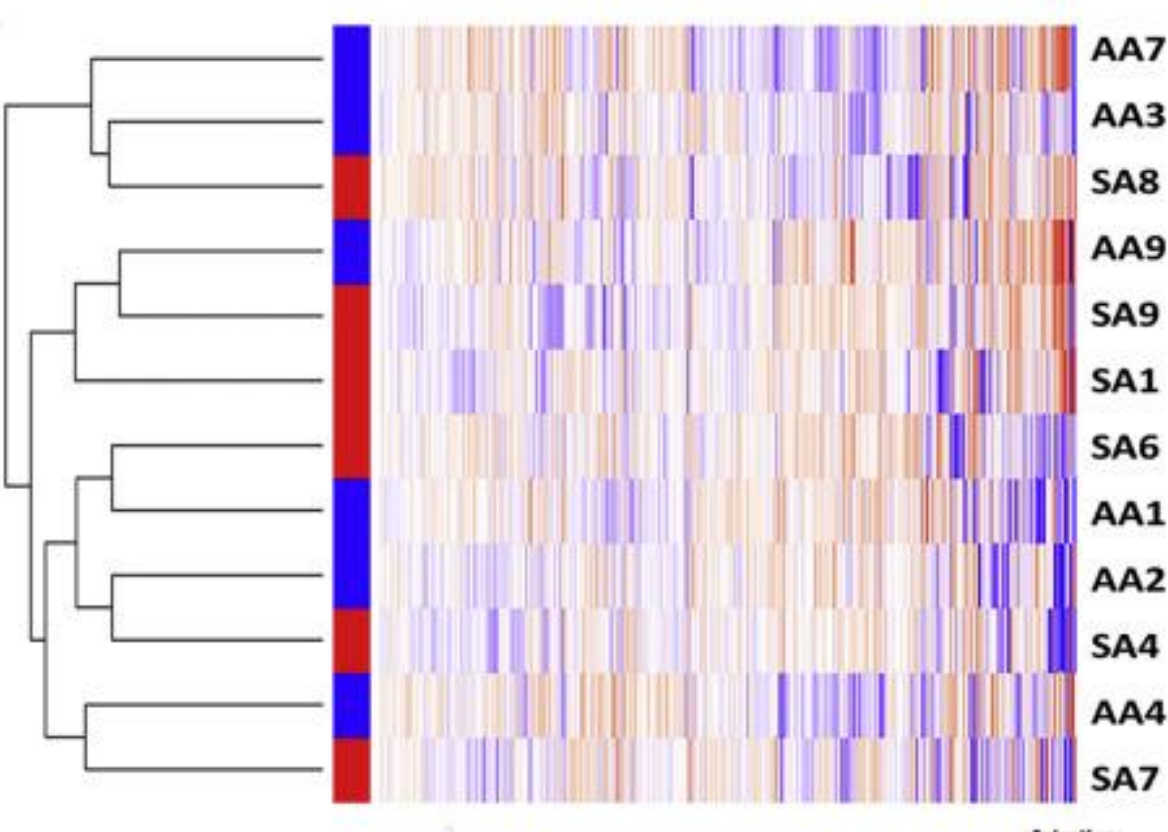

Binding (G0:0005488)

Catalytic Activity (GO:0003824)

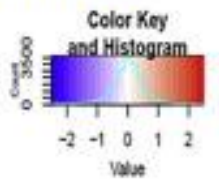

Molecular Function Regulator (GO:0098772)

Structural Molecule Activity (GO:0005198)

Translation Regulator Activity (GO:0045182) 
1. Download : Download high-res image (452KB)

2. Download: Download full-size image

Fig. 3. (A) Volcano plots for the normalized data (B) Clustering depending on correlation and protein expression profiles. Normalized data was used to build the heat map. Red indicates increased abundance; blue indicates lower abundance. (C) Molecular functions of differentially abundant proteins (green - AA; blue -SA). (For interpretation of the references to colour in this figure legend, the reader is referred to the web version of this article.)

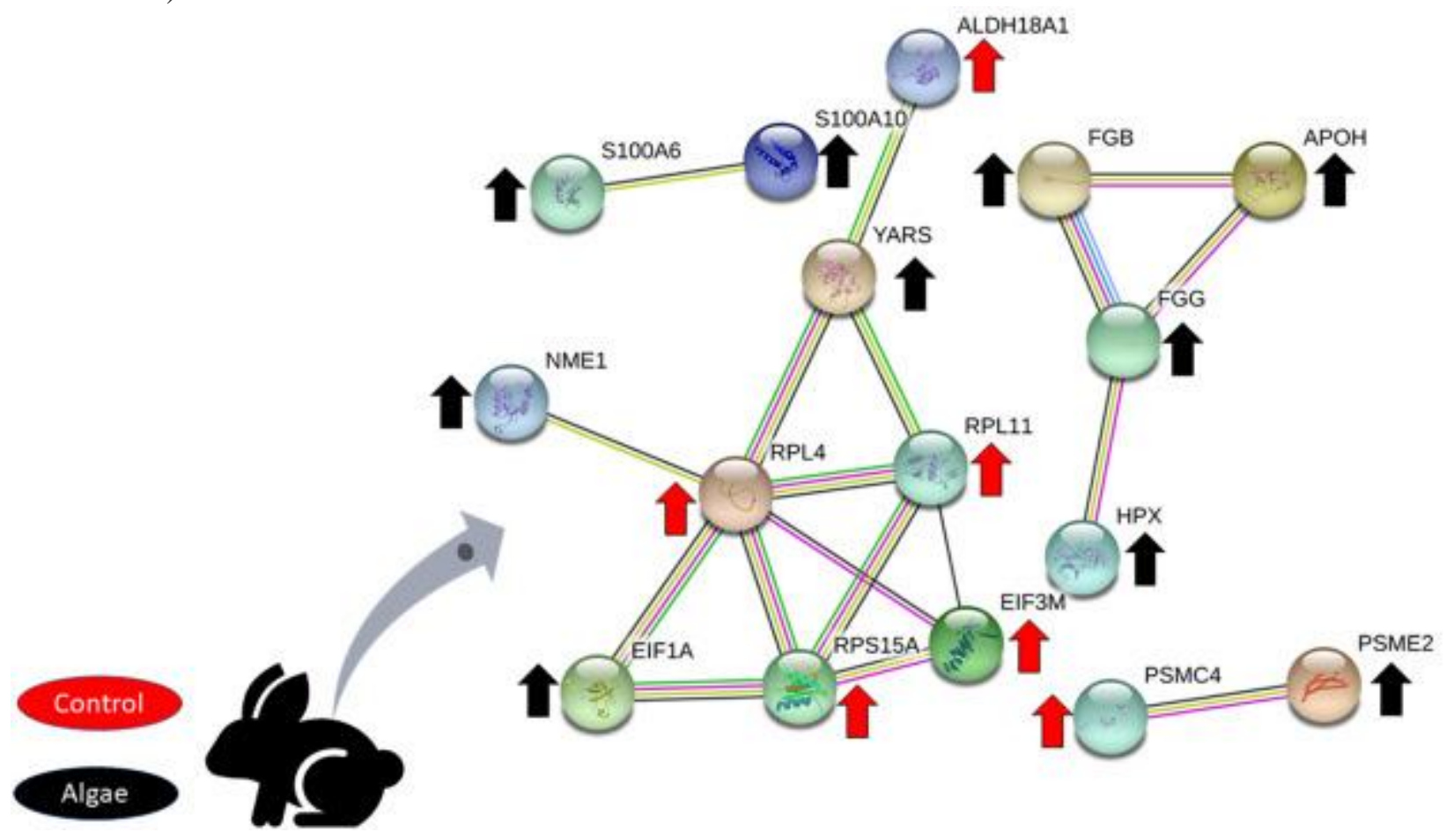

1. Download : Download high-res image (180KB)

2. Download : Download full-size image

Fig. 4. Interactions between differentially abundant proteins (red arrows - SA; black arrows - AA) in the rabbit gastrocnemius muscle proteome. S100A6 (Protein S100-A6), S100A10 (Protein S100-A10), ALDH18A1 (Delta-1-pyrroline-5-carboxylate synthase), YARS (Tyrosine-tRNA ligase), FGB (Fibrinogen beta chain), APOH (Uncharacterized protein), FGG (Uncharacterized protein), NME1 (Nucleoside diphosphate kinase), RPL4 (Uncharacterized protein), RPL11 (Uncharacterized protein), EIF3M (Eukaryotic translation initiation factor 3 subunit M), RPS15A (Uncharacterized protein), EIF1A (Uncharacterized protein), HPX (Hemopexin), PSMC4 (Proteasome 26S subunit, ATPase 4), PSME2 (Uncharacterized protein). (For interpretation of the references to colour in this figure legend, the reader is referred to the web version of this article.) 
The AA vs SA group comparison allowed the identification of 29 and 17 differentially abundant proteins (Table 2), respectively for each group. SA rabbits had higher abundance of proteins such as tropomyosin 3 (TPM3) and tropomodulin 4 (TMOD4), which are involved in muscle structural and contractile apparatus. In addition, SA rabbits had higher abundance of proteins related to protein catabolism and synthesis such as proteasome 26S subunit (PSMC4) and ribosomal proteins such as RPL4 and RPL11, respectively. Regarding the AA group, highly abundant proteins participate in a more heterogeneous range of pathways. Rabbits that were fed with NCO inclusion had higher abundance of proteins with antioxidative activity, such as glutaredoxin domain-containing protein (TXNRD1) that participates in cell redox homeostasis. They had also higher abundance of hemopexin (HPX), involved in cellular iron homeostasis and heme detoxification and L-lactate dehydrogenase (LDHA), which yields pyruvate. This group had highly abundant proteins involved in the amino acid metabolism, namely, glutamate-ammonia ligase (GLUL) and fumarylacetoacetase (FAH).

\section{Discussion}

Improving the nutritional value of meat is an effective way of reducing cardiovascular diseases $[\underline{6}, \underline{10]}$, which is particularly important in the current scenario, where meat consumption is steadily increasing in several regions of the world, particularly in developing countries [29]. If proven economically viable, using NCO in rabbit production diets could replace soybean-derived products, which would reduce the carbon footprint of the industry (by reducing import and/or unsustainable farming practices). In the following sections, animal performance and NCO feed inclusion will be discussed in relation with the muscle proteome of rabbits.

\subsection{Animal performance}

No parameter was affected by the use of NCO at a $4.45 \%$ dietary inclusion. This lack of impact in animal growth has been previously reported in studies aiming to modulate meat fatty acid profile using other sources of n-3 fatty acids [30]. With a dietary inclusion that goes up to 15\% of Spirullina, Peiretti and Meineri [11] have reported that only the diet with $10 \%$ inclusion had significant differences compared to 
control. In our study, despite the recalcitrant cell wall of NCO, rabbit growth performance was not significantly impaired. As such, it can be inferred that this microalgae at this inclusion rate can be an interesting alternative to soybean for rabbit diets. Additionally, to our knowledge, there are no significant effects of microalgae incorporation in the meat quality of rabbits reported in currently available literature [2]. Our results are coherent with these statements.

\subsection{Proteome characterization}

In the present study, $25 \%$ and $16.1 \%$ of the identified proteins are involved in cellular and metabolic processes, respectively. Interestingly, Liu et al. [16] have reported a similar number $(16.15 \%)$ of metabolism-related proteins in the sarcoplasmic reticulum proteome of rabbit skeletal muscle. Additionally, we report a $1.8 \%$ of the identified proteins as having a role in the response to stimulus, much less than the 5.18\% identified for muscle contraction according to the latter authors. The differences found between this and the latter study could result from different methodologies and enhanced databases. Similarly to other species $[\underline{18}, \underline{31}]$, rabbit muscle cell components are mostly cellular/intracellular, with $32.1 \%$ of the identified proteins belonging to this category. However, cattle's longissimus thoracis seems to have higher number of proteins involved in response to stimulus (5.9\%). Despite the obvious differences derived from comparing species, muscle type and development seem to exert variation between muscle proteomes. Overall, the characterization found was according to what would be expected in skeletal muscle.

\subsection{Differential protein abundance}

In this study, one comparison (AA vs SA) was performed to obtain differentially abundant proteins between groups. This approach is similar to what has been reported before for sheep muscle [18] and liver [32]. To our knowledge, it is the first time that the effect of NCO feed inclusion on rabbit muscle proteome is reported. The following sections discuss the proteins highly abundant in SA and in AA rabbits.

\subsubsection{Differential protein abundance in the SA group}

\subsubsection{Protein metabolism}


Control rabbits had higher abundance of proteins related to translation initiation and protein synthesis. Indeed, they had higher abundance of the eukaryotic translation initiation factor 3 (EIF3M) which is responsible for different processes that ultimately lead to protein synthesis [33]. In addition, they had higher abundance of ribosomal proteins: RPL4 and RPL11 which are constituents of ribosomes [34, $\underline{35]}$. The higher abundance of these proteins in SA rabbits points towards higher muscle development and/or growth rate via increased protein synthesis, which has been reported before in the muscle of Australian Merinos (high growth rate) compared to Damara (low growth rates) sheep [18]. However, this does not reflect the rabbit's final live weights. Instead, this could be a result of a possibly higher dietary amino acid availability in SA rabbits, which increases protein synthesis rates by comparison with the AA group. This is a mere possibility and despite the fact that crude protein digestibility of the diet has no significant differences between groups. In mammals, sulphured amino acids, namely methionine (Met) and cysteine (Cys), lead to increased protein synthesis $[36,37]$. In fact, Met is the main initiator of protein synthesis and Cys provides protein stability by forming disulphide bonds [38]. Sulphurated amino acids are lacking in several microalgae species [39]. Hence, the relation found for ribosomal proteins could be a direct result of the recalcitrant cell wall of NCO, which seemingly lowers amino acid digestibility in monogastric animals [5]. A similar relation was found for other amino acids such as lysine (Lys), valine (Val), isoleucine (Iso) and leucine (Leu), the latter being an important stimulator for muscle protein synthesis [37]. In fact, a reduction in overall essential amino acid availability would impair mRNA translation itself, by upregulating the mGCN2 (general control non-depressing kinase) protein which phosphorylates the eIF $2 \alpha$ translation factor that ultimately leads to reduced mRNA translation [40]. The branched-chain amino acid Leu is particularly important to signal the mammalian target of rapamycin 1 (mTORC1) pathway, which ultimately leads to protein synthesis [37]. Therefore, if the negative effect of the NCO recalcitrant cell wall over amino acid digestibility seen in rabbits, it would be expectable for SA rabbits to have higher muscle protein synthesis in comparison to AA rabbits. Further research in these aspects are therefore pressing and interesting to be conducted in the future.

Conversely, a proteasome-related protein was more abundant in SA rabbits, namely PSMC4. These proteins are included in the multi-enzyme complex involved in 
proteolysis [41], in contrast to ribosomal proteins that synthetize them. Indeed, the proteasome is involved in meat tenderization, by degrading myofibrillar proteins [42]. However, there is no difference in abundance of structural proteins such as myosin in the present study. In fact, contractile apparatus proteins are more abundant in SA rabbits, as will be discussed in the following section. Moreover, no statistically significant differences were found for the crude protein content of leg meat between experimental groups. Therefore, this relation between ribosomal and proteasome proteins suggests higher rates of protein turn-over in SA rabbits, which could also originate from higher availability of amino acids, thus explaining the lack of differences between live weights of both groups. Again, this is an interesting possibility that may open interesting avenues for research in the future.

\subsubsection{Contractile apparatus proteins and meat tenderness}

Tropomyosin 3 (TPM3) and tropomodulin 4 (TMOD4) were found to have higher abundance in SA rabbits. These are contractile apparatus proteins. Tropomyosin chains have been previously identified in higher abundance in the gastrocnemius muscle of wild Iberian rabbits (Oryctolagus cuniculus algirus), particularly in those nutritionally restricted, compared to New Zealand white rabbits [15]. In another study aiming to study the response of sheep breeds to weight loss, TPM3 was found to be highly abundant in the gastrocnemius of Dorper lambs fed unrestricted diets compared to those that were nutritionally restricted [18]. In the former study, this protein was suggested as a putative biomarker of weight loss whereas in the latter it was related to higher muscle development of unrestricted Dorper lambs. Additionally, two other studies have appointed higher abundance of TPM to higher muscle development in nutritionally unrestricted Boer goat bucks [43] and continuous growth Alentejana bulls [31]. The higher abundance of muscle structure proteins of SA rabbits is supported by the protein synthesis results described above, regardless of not being reflected by LW results. Additionally, the higher abundance of TPM3 and TMOD4 in SA rabbits could have an impact in meat tenderness, decreasing it when compared to AA rabbits. Lametsch and co-workers [44] have previously reported how other contractile apparatus proteins are related to pig meat tenderness. Studies on broiler chickens have been contradictory regarding the effect of microalgae dietary inclusion on meat tenderness whereas 
studies involving pigs report no effect whatsoever [2]. However, an increased meat tenderness in quails fed diets containing 4 and 8\% Spirulina has been reported [45]. Also, keratocan (KERA), an atypical protein to be identified in the muscle tissue [46], was found to be highly abundant in SA rabbits. This protein belongs to the proteoglycan family and is responsible for stabilizing collagen fibrils in the extracellular matrix of the cornea [47]. If positively related to collagen synthesis, this higher abundance further supports our premise that SA muscle is less tender, since collagen is negatively related to meat tenderness [48]. Further studies involving NCO inclusion in rabbit diets will be needed to evaluate meat tenderness and the corresponding proteome response.

\subsubsection{Differential protein abundance in the experimental group}

\subsubsection{Muscle protein breakdown}

L-lactate dehydrogenase (LDHA) was found to be highly abundant in AA rabbits. Authors have reported it to be highly abundant in the skeletal muscle of underfed rabbits [15] and continuous growth Alentejana bulls [31]. The former referenced authors have suggested LDHA to be considered a marker of protein breakdown, characteristic of a catabolic state. Additionally, it has been proven before that Leu, for example, is a regulator of protein synthesis. Low availability of Leu is reported to lower overall muscle protein synthesis [49]. This could be the cause for a higher abundance of a protein breakdown biomarker in rabbits fed with NCO, as they could have lower availability of some amino acids, as mentioned previously. Lack of amino acids has been related to impaired muscle protein synthesis [50]. Additionally, calpain-1 catalytic subunit (CAPN1) has been found in higher abundance in the muscle of AA rabbits. The CAPN1 protein is a Ca-activated enzyme that participates in muscle protein breakdown [41] and is deeply involved in muscle-to-meat tenderization [42]. The higher abundance of CAPN1 also agrees with the other possibility mentioned previously, that AA meat might be more tender. Indeed, calpain is the main contributor to meat tenderness [51]. The assessment of meat quality data from rabbits fed with NCO inclusion would be of high interest to test this possibility, as mentioned above.

\subsubsection{Amino acid metabolism}


Rabbits fed with NCO had higher abundance of glutamate-ammonia ligase (GLUL), which is an enzyme that catalyses a reaction that leads to glutamine (Gln) synthesis. Gln is a non-essential amino acid synthetized in the muscle from circulating branchchain amino acids (BCAA) [37]. Authors have reported that the net protein uptake of rat diets containing $\mathrm{NCO}$ is similar to a control diet without it [39], similarly to what occurs in the present study (no differences regarding crude protein digestibility). However, the latter authors have disrupted the cell walls prior to feed incorporation, which could answer why an inclusion level 15\% had no negative effect over the protein uptake. In our study, no cell wall disruption was used to process NCO prior to feed inclusion. Skrede et al. [4] have reported an average apparent digestibility of all BCAA around 30\% using mink as a model for monogastric animals, which would decrease their availability for Gln synthesis. Interestingly, low Gln levels are related to negative protein balance in the muscle tissue. Indeed, Gln stimulates protein synthesis and inhibits its degradation [37]. The higher abundance of GLUL points towards increased Gln concentration, hence higher protein synthesis. However, under higher catabolic rates, BCAA are degraded in the muscle, forming glutamate and branched-chain keto acids [43]. Glutamate is the main substrate used by GLUL to form Gln, along with ammonia and ATP. Therefore, higher GLUL activity could derive from the utilization of Glu formed during BCAA catabolism. In fact, a high catabolism of Leu (a BCAA) in AA rabbits would corroborate what has been discussed previously for SA rabbits regarding protein synthesis, because Leu stimulates muscle protein synthesis via the mammalian target of rapamycin complex 1 (mTORC1) [52]. Additionally, tyrosine (Tyr) and phenylalanine (Phe) also seem to be degraded, since fumarylacetoacetate hydrolase (FAH) was found in higher abundance in AA rabbits. This latter enzyme catalyses the last step of Tyr and Phe catabolism, generating acetoacetate and fumarate [53]. The latter enters the citric acid cycle and the former is oxidized in peripheral non-hepatic tissues or converted into acetone. Thus, the lower availability of BCAA in AA rabbits would increase GLUL abundance. In addition, this group appears to degrade Phe and Tyr at higher rates, using the resulting fumarate for energy production.

\subsubsection{Other pathways}


Ribokinase (RBKS) was highly abundant in AA rabbits. This enzyme catalyses the reaction that converts D-ribose into D-ribose 5-phosphate, which then becomes available for to enter the pentose phosphate pathway [54]. This pathway yields generous amounts of NADPH, which is involved in various reactions/pathways: fatty acid synthesis, reduction of glutathione (converts $\mathrm{H}_{2} \mathrm{O}_{2}$ into $\mathrm{H}_{2} \mathrm{O}$ ), synthesis of proline, among many others [53]. The higher rates of pentose phosphate pathway could be related to higher needs for NADPH, particularly for pathways related to fatty acid synthesis and antioxidant activity. In fact, authors have reported that increased dietary ribose availability does not increase RBKS expression in mouse skeletal muscle [55], which points towards our differences not resulting from a hypothetical increase in feed digestibility. Ultimately, higher RBKS abundance supports our premise that there are higher needs of NADPH in AA rabbit muscle.

Rabbits fed with NCO inclusion had higher abundance of hemopexin (HPX). This is a protein with high affinity to heme. Iron bound to heme is a contributor towards the cellular synthesis of toxic hydroxyl radicals [56]. HPX binds muscle heme and transports it to the liver, where it is catabolized, and the reactive iron is bound to ferritin [56]. This contributes to improved antioxidant status of the muscle tissue in rabbits that are fed with $\mathrm{NCO}$, by avoiding tissue damage by reactive oxygen species such as $\mathrm{H}_{2} \mathrm{O}_{2}$. Interestingly, authors have related HPX to adipogenesis, even correlating its expression with triglycerides in humans and mice [57]. In our study, this differential abundance of HPX could result from the enrichment of meat with n-3 PUFA. In addition, oxidative stress - related proteins, along with other factors such as calpain and glycolytic enzymes expression, have been related to meat tenderness/tenderness formation [51], which supports increased meat quality of AA rabbits. However, evaluating meat tenderness in the future is necessary to validate this hypothesis.

\section{Conclusions and future perspectives}

In this study, we have described the changes in the muscle proteome of rabbits fed with NCO at an inclusion level of $4.45 \%$. We report the absence of differences in crude protein content in the leg muscle of rabbits. This information combined with our proteomic results where SA rabbits have simultaneously higher abundance of protein 
synthesis and catabolism-related proteins, point towards increased protein turnover rates in SA rabbits. We postulate that this is possibly due to the decreased amino acid digestibility in the NCO diet, as reported in other monogastric species. In addition, the increased protein turnover of SA rabbits seems to be related with the abundance of structural/contractile apparatus proteins in parallel, which are known to be negatively related to meat tenderness. By contrast, AA rabbits have higher abundance of calpain, a protein of paramount importance for the development of meat tenderness. In this trial, we have not conducted an assessment of meat tenderness nor amino acid digestibility. Thus, it would be important to include this data in future experiments.

Our results point towards interesting possibilities regarding the effect of dietary NCO over amino acid metabolism and meat tenderness. Additionally, the fatty acid profile of this tissue has been studied to assess whether or not the rabbit is capable of using NCO as a functional feed towards the increase of n-3 PUFA contents, particularly of EPA. These results will be presented in a companion paper. The hypothesisgenerating approach of the present study opens a wide range of possibilities and demonstrates the potential of using proteomics in nutritionally oriented studies using farm animals. The validation of our results by determining the amino acid profile of meat as well as tenderness would be highly interesting. In addition, further alternatives could be adopted to increase the nutrient availability of NCO, since pelleting seems to be insufficient to enhance its amino acid digestibility. Namely, considering the use of enzymes in feed formulations could prove itself useful in rabbit diets for this purpose.

Finally, it is important to point out that amino acid digestibility would be a very interesting addition to further study and confirm our previous statements. Such approach could be accomplished, for instance by using ileum-cannulated rabbits, mostly due to the particularities of the digestive tract of the rabbit.

\section{Acknowledgements}

Authors acknowledge funding from FCT - Fundação para a Ciência e a Tecnologia (Lisbon, Portugal) in the form of Research Center Programs LEAF (Linking Landscape, Environment, Agriculture and Food: authors AA, JB, DR, 
CM and LFC), CIISA (Interdisciplinary Animal Health Research Center: authors RB and SA) and the PhD grant $\underline{\mathrm{SFRH} / \mathrm{BD} / 143992 / 2019}$ awarded to DR.

\section{Appendix A. Supplementary data}

Download : Download spreadsheet (764KB)

Supplementary table 1 - Proteins identified in a AA vs SA comparison

\section{References}

[1]

J. Eise, K. Foster

How to Feed World

(2018), pp. 1-250, 10.5822/978-1-61091-885-5

View Record in ScopusGoogle Scholar

[2]

M.S. Madeira, C. Cardoso, P.A. Lopes, D. Coelho, C. Afonso, N.M. Bandarra, J.A.M. Prates

Microalgae as feed ingredients for livestock production and meat quality: a review

Livest. Sci., 205 (2017), pp. 111-121, 10.1016/j.livsci.2017.09.020

ArticleDownload PDFView Record in ScopusGoogle Scholar

[3]

C.S.C. Mota

Avaliação do potencial de utilização de microalgas como alimento alternativo na alimentação de animais de produção (MSc thesis)

University of Porto (2018)

$\underline{\text { Google Scholar }}$

[4]

A. Skrede, L. Mydland, $\varnothing$. Ahlstrøm, K. Reitan, H. Gislerød, M. Øverland

Evaluation of microalgae as sources of digestible nutrients for monogastric animals

J. Anim. Feed Sci., 20 (2016), pp. 131-142, 10.22358/jafs/66164/2011

$\underline{\text { Google Scholar }}$ 
K.K. Lum, J. Kim, X.G. Lei

Dual potential of microalgae as a sustainable biofuel feedstock and animal feed

J. Anim. Sci. Biotechnol., 4 (2013), pp. 1-7, 10.1186/2049-1891-4-53

View Record in ScopusGoogle Scholar

[6]

S.P. Alves, S.H. Mendonça, J.L. Silva, R.J.B. Bessa

Nannochloropsis oceanica, a novel natural source of rumen-protected eicosapentaenoic acid (EPA) for ruminants

Sci. Rep., 8 (2018), pp. 2-11, 10.1038/s41598-018-28576-7

\section{CrossRefGoogle Scholar}

[7]

K.G. Benner, A. Sasaki, D.R. Gowen, A. Weaver, W.E. Connor

The differential effect of eicosapentaenoic acid and oleic acid on lipid synthesis and VLDL secretion in rabbit hepatocytes

Lipids., 25 (1990), pp. 534-540, 10.1007/BF02537160

View Record in Scopus Google Scholar

B.W.B. Holman, A.E.O. Malau-Aduli

Spirulina as a livestock supplement and animal feed

J. Anim. Physiol. Anim. Nutr. (Berl)., 97 (2013), pp. 615-623, 10.1111/j.1439-0396.2012.01328.x

\section{CrossRefView Record in ScopusGoogle Scholar}

I. Miller, C. Rogel-Gaillard, D. Spina, L. Fontanesi, A. de Almeida

The rabbit as an experimental and production animal: from genomics to proteomics

Curr. Protein Pept. Sci., 15 (2014), pp. 134-145, 10.2174/1389203715666140221115135

\section{CrossRefView Record in ScopusGoogle Scholar}

R.G. Li, X.P. Wang, C.Y. Wang, M.W. Ma, F.C. Li

Growth performance, meat quality and fatty acid metabolism response of growing meat rabbits to dietary linoleic acid

Asian-Australas. J. Anim. Sci., 25 (2012), pp. 1169-1177, 10.5713/ajas.2012.12085 
P.G. Peiretti, G. Meineri

Effects of diets with increasing levels of Spirulina platensis on the performance and apparent digestibility in growing rabbits

Livest. Sci., 118 (2008), pp. 173-177, 10.1016/j.livsci.2008.04.017

ArticleDownload PDFView Record in ScopusGoogle Scholar

A.L. Mordenti, L. Sardi, A. Bonaldo, V. Pizzamiglio, N. Brogna, I. Cipollini, M. Tassinari, G. Zaghini

In fl uence of marine algae (Schizochytrium spp.) dietary supplementation on doe performance and progeny meat quality

Livest. Sci., 128 (2010), pp. 179-184, 10.1016/j.livsci.2009.12.003

ArticleDownload PDFView Record in ScopusGoogle Scholar

B. Howe

Nannochloropsis oculata: A Safe Protein Feed for Growig Rats and Rabbits (PhD thesis)

Colorado State University (2012)

$\underline{\text { Google Scholar }}$

A.M. Almeida, A. Campos, S. van Harten, L.A. Cardoso, A.V. Coelho

Establishment of a proteomic reference map for the gastrocnemius muscle in the rabbit (Oryctolagus cuniculus)

Res. Vet. Sci., 87 (2009), pp. 196-199, 10.1016/i.rvsc.2009.02.011

ArticleDownload PDFView Record in ScopusGoogle Scholar

A.M. Almeida, A. Campos, R. Francisco, S. Van Harten, L.A. Cardoso, A.V. Coelho 
Proteomic investigation of the effects of weight loss in the gastrocnemius muscle of wild and NZW rabbits via 2D-electrophoresis and MALDI-TOF MS

Anim. Genet., 41 (2010), pp. 260-272, 10.1111/j.1365-2052.2009.01994.X

CrossRefView Record in ScopusGoogle Scholar

Z. Liu, X. Du, C. Yin, Z. Chang

Shotgun proteomic analysis of sarcoplasmic reticulum preparations from rabbit skeletal muscle

Proteomics., 13 (2013), pp. 2335-2338, 10.1002/pmic.201200138

CrossRefView Record in ScopusGoogle Scholar

Z. Liu, X. Du, J. Deng, M. Gu, H. Hu, M. Gui, C.C. Yin, Z. Chang

The interactions between mitochondria and sarcoplasmic reticulum and the proteome characterization of mitochondrion-associated membrane from rabbit skeletal muscle Proteomics., 15 (2015), pp. 2701-2704, 10.1002/pmic.201400493

CrossRefView Record in ScopusGoogle Scholar

A.M. Ferreira, J. Grossmann, C. Fortes, T. Kilminster, T. Scanlon, J. Milton, J. Greeff, C. Oldham, P. Nanni, A.M. Almeida

The sheep (Ovis aries) muscle pro- teome: decoding the mechanisms of tolerance to seasonal weight loss using label- free proteomics

J. Proteome, 161 (2017), pp. 57-67, 10.1016/i.jprot. 2017.03.020

ArticleDownload PDFView Record in ScopusGoogle Scholar 
D.M. Ribeiro, S. Planchon, C.C. Leclercq, K. Raundrup, S.P. Alves, R.J.B. Bessa, J. Renaut, A.M. Al meida

The muscular, hepatic and adipose tissues proteomes in muskox (Ovibos moschatus): differences between males and females

J. Proteome, 208 (2019), p. 103480, 10.1016/j.jprot.2019.103480

ArticleDownload PDFView Record in ScopusGoogle Scholar

J.M. Pérez, F. Lebas, T. Gidenne, L. Maertens, G. Xiccato, R. Parigi-Bini, Zotte A. Dalle

European reference method for in vivo determination of diet digestibility in rabbits World Rabbit Sci., 3 (2010), 10.4995/wrs.1995.239

$\underline{\text { Google Scholar }}$

C. Martins, M. Cullere, A. Dalle Zotte, C. Cardoso, S.P. Alves, R.J.B. Bessa, J.P.B. Freire, L. Falcão e Cunha

Incorporation of two levels of Black Soldier Fly (Hermintia illucens L.) larvae fat or extruded linseed in diets of growing rabbits: effects on growth performance and diet digestibility Czech J. Anim. Sci., 63 (2018), pp. 356-362, 10.17221/22/2018-CJAS

View Record in ScopusGoogle Scholar

Y. Zhu, C. Wang, X. Wang, B. Li, F. Li

Effect of dietary fiber/starch balance on the cecal proteome of growing rabbits

J. Proteome, 103 (2014), pp. 23-34, 10.1016/j.jprot.2014.03.019

$\underline{\text { ArticleDownload PDFView Record in ScopusGoogle Scholar }}$ 
Antonella Dalle Zotte, Marco Cullere, Cátia Martins, Susana P. Alves, João

P.B. Freire, Luísa Falcão-e-Cunha, Rui J.B. Bessa

Incorporation of Black Soldier Fly (Hermetia illucens L.) larvae fat or extruded linseed in diets of growing rabbits and their effects on meat quality traits including detailed fatty acid composition

Meat Sci. (2018), 10.1016/j.meatsci.2018.08.002

Google Scholar

C. Türker, F. Akal, D. Joho, C. Panse, S. Barkow-Oesterreicher, H. Rehrauer, R. Schlapbach

B-fabric: The Swiss army knife for life sciences

Adv. Database Technol. - EDBT 2010 - 13th Int. Conf. Extending Database Technol. Proc (2010), pp. 717-720, 10.1145/1739041.1739135

CrossRefView Record in ScopusGoogle Scholar

J. Cox, M. Mann

MaxQuant enables high peptide identification rates, individualized p.p.b.-range mass accuracies and proteome-wide protein quantification

Nat. Biotechnol., 26 (2008), pp. 1367-1372, 10.1038/nbt.1511

CrossRefView Record in ScopusGoogle Scholar

Witold Wolski, Jonas Grossmann, Christian Panse

SRMService - R-Package to Report Quantitative Mass Spectrometry Data

http://github.com/protViz/SRMService (2018)

Google Scholar 
H. Mi, A. Muruganujan, P.D. Thomas

PANTHER in 2013: Modeling the evolution of gene function, and other gene attributes, in the context of phylogenetic trees

Nucleic Acids Res., 41 (2013), pp. 377-386, 10.1093/nar/gks1118

\section{$\underline{\text { Google Scholar }}$}

D. Szklarczyk, A.L. Gable, D. Lyon, A. Junge, S. Wyder, J. Huerta-

Cepas, M. Simonovic, N.T. Doncheva, J.H. Morris, P. Bork, L.J. Jensen, C. Von Mering

STRING v11: protein-protein association networks with increased coverage, supporting functional discovery in genome-wide experimental datasets

Nucleic Acids Res., 47 (2019), pp. D607-D613, 10.1093/nar/gky1131

CrossRefView Record in ScopusGoogle Scholar

FAO

Prospects for aggregate agriculture and major commodity groups

J. Bruinsma (Ed.), World Agriculture: Towards 2015/2030, Routledge, London (2003), pp. 57-123

View Record in ScopusGoogle Scholar

L. Menchetti, C. Canali, C. Castellini, C. Boiti, G. Brecchia

The different effects of linseed and fish oil supplemented diets on insulin sensitivity of rabbit does during pregnancy

Res. Vet. Sci., 118 (2018), pp. 126-133, 10.1016/i.rvsc.2018.01.024 
A.M. Almeida, P. Nanni, A.M. Ferreira, C. Fortes, J. Grossmann, R.J.B. Bessa, P. Costa

The longissimus thoracis muscle proteome in Alentejana bulls as affected by growth path J. Proteome, 152 (2017), pp. 206-215, 10.1016/j.jprot.2016.10.020

ArticleDownload PDFView Record in ScopusGoogle Scholar

B. Miller, N. Selevsek, J. Grossmann, T. Kilminster, T. Scanlon, M. Daniels, P. Nanni, J. Milton, C. Oldham, J. Greeff, A. Chapwanya, D. Bergfelt, A.M. de Almeida

Ovine liver proteome: assessing mechanisms of seasonal weight loss tolerance between merino and Damara sheep

J. Proteome, 191 (2019), pp. 180-190, 10.1016/j.jprot.2018.02.018

$\underline{\text { ArticleDownload PDFView Record in ScopusGoogle Scholar }}$

UniProt, Eukaryotic Translation Initiation Factor 3

n.d.

https://www.uniprot.org/uniprot/G1SLW8, Accessed 13th Nov 2019

$\underline{\text { Google Scholar }}$

UniProt, Ribosomal Protein

n.d.

https://www.uniprot.org/uniprot/G1TY53, Accessed 13th Nov 2019 
60S Acidic Ribosomal Protein

n.d.

https://www.uniprot.org/uniprot/G1SPK4, Accessed 13th Nov 2019

Google Scholar

O.W. Griffith

Mammalian sulfur amino acid metabolism: an overview

Methods Enzymol., 143 (1987), pp. 366-376, 10.1016/0076-6879(87)43065-6

ArticleDownload PDFView Record in ScopusGoogle Scholar

G. Wu

Amino acids: metabolism, functions, and nutrition

Amino Acids, 37 (2009), pp. 1-17, 10.1007/s00726-009-0269-0

CrossRefView Record in ScopusGoogle Scholar

J.T. Brosnan, M.E. Brosnan

The sulfur-containing amino acids: an overview

J. Nutr., 136 (2006), pp. 1636S-1640S, 10.1093/in/136.6.1636S

CrossRefGoogle Scholar 
U. Neumann, F. Derwenskus, A. Gille, S. Louis, U. Schmid-Staiger, K. Briviba, S.C. Bischoff

Bioavailability and safety of nutrients from the microalgae Chlorella vulgaris, Nannochloropsis oceanica and Phaeodactylum tricornutum in C57BL/6 mice

Nutrients, 10 (2018), 10.3390/nu10080965

Google Scholar

S.R. Kimball, L.S. Jefferson

Amino acids as regulators of gene expression

Nutr. Metab., 1 (2004), pp. 1-10, 10.1186/1743-7075-1-3

View Record in Scopus Google Scholar

J. Huang, N.E. Forsberg

Role of calpain in skeletal-muscle protein degradation

Proc. Natl. Acad. Sci. U. S. A., 95 (1998), pp. 12100-12105, 10.1073/pnas.95.21.12100

View Record in ScopusGoogle Scholar

J.M. Malheiros, C.P. Braga, R.A. Grove, F.A. Ribeiro, C.R. Calkins, J. Adamec, L.A.L. Chardulo

Influence of oxidative damage to proteins on meat tenderness using a proteomics approach Meat Sci., 148 (2019), pp. 64-71, 10.1016/j.meatsci.2018.08.016

ArticleDownload PDFView Record in ScopusGoogle Scholar 
A.M. Almeida, L.M.J. Schwalbach, H.O. DeWaal, J.P.C. Greyling, L.A. Cardoso

Serum amino acid and myofibrillar protein profiles in Boer goat bucks following undernutrition

Small Rumin. Res., 55 (2004), pp. 141-147, 10.1016/j.smallrumres.2004.01.009

ArticleDownload PDFView Record in ScopusGoogle Scholar

R. Lametsch, A. Karlsson, K. Rosenvold, H.J. Andersen, P. Roepstorff, E. Bendixen

Postmortem proteome changes of porcine muscle related to tenderness

J. Agric. Food Chem., 51 (2003), pp. 6992-6997, 10.1021/if034083p

View Record in Scopus Google Scholar

D.S.W. Cheong, A. Kasim, A.Q. Sazili, H. Omar, J.Y. Teoh

Effect of supplementing spirulina on live performance, carcass composition and meat quality of Japanese quail

Walailak J. Sci. Technol., 13 (2016), pp. 77-84

View Record in ScopusGoogle Scholar

L.M. Corpuz, J.L. Funderburgh, M.L. Funderburgh, G.S. Bottomley, S. Prakash, G.W. Conrad Molecular cloning and tissue distribution of keratocan

J. Biol. Chem., 271 (1996), pp. 9759-9763, 10.1074/jbc.271.16.9759

ArticleDownload PDFView Record in ScopusGoogle Scholar 
E. Lorenzo-Martín, P. Gallego-Muñoz, S. Mar, I. Fernández, P. Cidad, M.C. Martínez-García

Dynamic changes of the extracellular matrix during corneal wound healing

Exp. Eye Res., 186 (2019), p. 107704, 10.1016/i.exer.2019.107704

ArticleDownload PDFView Record in ScopusGoogle Scholar

A.R. Weston, R.W. Rogers, T.G. Althen

Reviews: the role of collagen in meat tenderness

Prof. Anim. Sci., 18 (2002), pp. 107-111, 10.15232/S1080-7446(15)31497-2

ArticleDownload PDFView Record in ScopusGoogle Scholar

S. Mordier, C. Deval, D. Béchet, A. Tassa, M. Ferrara

Leucine limitation induces autophagy and activation of lysosome-dependent proteolysis in C2C12 myotubes through a mammalian target of rapamycin-independent signaling pathway J. Biol. Chem., 275 (2000), pp. 29900-29906, 10.1074/jbc.M003633200

ArticleDownload PDF $\underline{\text { View Record in ScopusGoogle Scholar }}$

R.R. Wolfe

Supplement : protein metabolism in response to ingestion pattern and composition of proteins regulation of muscle protein by amino acids

J. Nutr. (2002), pp. 3219-3224

$\underline{\text { Google Scholar }}$

E. Veiseth-Kent, A.M. de Almeida, B. Picard, K. Hollung

Proteomics in skeletal muscle research

A.M. Almeida, D. Eckersal, I. Miller (Eds.), Proteomics Domest. Anim. From Farm to Syst.

Biol, Springer International Publishing, Cham (2018), pp. 195-217, 10.1007/978-3-319-69682-

$9 \quad 10$

CrossRefView Record in ScopusGoogle Scholar

T. Moro, S.M. Ebert, C.M. Adams, B.B. Rasmussen 
Amino acid sensing in skeletal muscle

Trends Endocrinol. Metab., 27 (2016), pp. 796-806, 10.1016/i.tem.2016.06.010

$\underline{\text { ArticleDownload PDFView Record in ScopusGoogle Scholar }}$

G. $\mathrm{Wu}$

Principles of Animal Nutrition

Taylor \& Francis Group, Boca Raton, FL (2018)

$\underline{\text { Google Scholar }}$

UniProt, Ribokinase

n.d.

https://www.uniprot.org/uniprot/G1SZT1, Accessed 13th Nov 2019

$\underline{\text { Google Scholar }}$

W. Coley, S. Rayavarapu, J.H. van der Meulen, A.S. Duba, K. Nagaraju

Daily supplementation of D-ribose shows no therapeutic benefits in the MHC-I transgenic mouse model of inflammatory myositis

PLoS One, 8 (2013), 10.1371/journal.pone.0065970

$\underline{\text { Google Scholar }}$

E. Tolosano, F. Altruda

Hemopexin: structure, function, and regulation

DNA Cell Biol., 21 (2002), pp. 297-306, 10.1089/104454902753759717

CrossRefView Record in ScopusGoogle Scholar

H.A. Lawson, M. Zayed, J.P. Wayhart, E. Fabbrini, L. Love-Gregory, S. Klein, C.F. Semenkovich

Physiologic and genetic evidence links hemopexin to triglycerides in mice and humans Int. J. Obes., 41 (2017), pp. 631-638, 10.1038/ijo.2017.19

CrossRefView Record in ScopusGoogle Scholar 